\title{
El poeta, el filósofo, el médico: estúdio del sufrimiento
}

Andrés Eduardo Aguirre Antúnez*1

Gilberto Safra*2

El presente trabajo realiza una interlocución entre un poeta, un fenomenólogo y un psicopatólogo donde el eje común es la clínica terapéutica y una comprensión posible de la psicopatología en diálogo interdisciplinar. Observamos que la literatura, la filosofía y la medicina psiquiátrica contribuyen para comprender el sufrimiento humano no solo como una manifestación intrapsíquica, pero íntimamente relacionado a la sensibilidad, la afectividad y la vivencia personal del tiempo y espacio humanos en dirección a factores ambientales y culturales.

Palabras claves: Literatura, fenomenología, psicopatología, psicología clínica

${ }^{* 1}$ Universidade de São Paulo - USP (São Paulo, SP, Br).

*2 Universidade de São Paulo - USP (São Paulo, SP, Br). 
Ai, el tiempo avanza con ceniza, con aire y con agua! La piedra que han mordido el légamo y la angustia florece de pronto con estruendo de mar, y la pequeña rosa vuelve a su delicada tumba de corola.

(Neruda, 2003, Conducta y Poesía, Para nacer he nacido, p. 199)

La interlocución entre un poeta, un fenomenólogo y un psicopatólogo son tomadas para reflexionar la clínica terapéutica, de modo a buscar una comprensión posible de la psicopatología en diálogo interdisciplinar. Observamos que las formas artísticas de la literatura, la filosofía y la medicina psiquiátrica contribuyen para comprender el sufrimiento humano no solo como una manifestación intrapsíquica, pero íntimamente relacionado a la sensibilidad, a la afectividad y la vivencia personal del tiempo y espacio humanos en dirección a factores ambientales, política y cultural. Neruda (2003) escribe "Para nacer he nacido" (...) y "para encerrar el paso de cuanto se aproxima, de cuanto a mi pecho golpea como un nuevo corazón tembloroso". El temblor de la Cordillera de los Andes parece una manifestación de un monstro sagrado que despierta sus roncos temblores de tierra que afectan, de modos muy particular y universal, el poeta, como a todo ser humano en el íntimo de su vulnerabilidad. Neruda era casado con la naturaleza humana, unido a las cosas y a la naturaleza misma. La creación literaria, compañera de su soledad, atinge más allá de lo que podría imaginar: toca desde adentro de la clínica.

La psicopatología que nos acompañará no será la del DSM-V o de la CID-10, ni la psicoanalítica, pero aquella que se acerca a las vivencias descritas y vividas en su forma pura, original y relacional, la psicopatología fenomenológica de Eugène Minkowski.

"Me niego a masticar teorías" (Neruda, 2003, p. 132). La fenomenología coloca entre paréntesis o suspensión los preconceptos, perjuicios y teoría de las cosas y busca la esencia del fenómeno. De acuerdo con Henry (1963/2011) es la fenomenalidad de la afectividad la esencia de la Vida, la auto-afección de Si en alteridad.

El sufrimiento psiquiátrico, humano, está en toda parte, en vecinos, amigos, desconocidos, en familia, en el trabajo. Si queremos conocer la poesía de Neruda o la poética de un paciente, que se escuche sintiendo lo que ellos dicen, a su modo, en su tiempo, en su idioma personal (Safra, 2006). Escuchando no solo de forma analítica, pero escuchando al modo como nuestro cuerpo reacciona delante la alteridad, así como al leer los poemas que nos tocan en el corazón, en el sentimiento.

Interesante cuando Neruda (2003) fue convidado a agradecer a la traducción de tres amigos brasileños de sus obras. El poeta expresó: "No sé qué decir 


\section{MOVIMENTOS LITERÁRIOS}

ni por dónde comenzar. Tengo ya 53 años y nunca he sabido que es la poesía, ni cómo definir lo que no conozco. No he podido tampoco aconsejar a nadie sobre esta sustancia oscura y la vez deslumbrante" (p. 132). ¿Como hacer un diálogo entre psicopatología y la fenomenología de la vida de Michel Henry? ¿La sustancia oscura y deslumbrante que el poeta cuestiona, no sería la propia vida?

La psicopatología que nos toca no es aún la del exterior, tampoco solamente la que nasce de nuestra interioridad, pero la que ocurre entre dos pathos, en terminología henryana en co-pathos. Pathos comprendido en su origen griega, sufrimiento y placer. Los terapeutas deben proporcionar en la relación interhumana el crecimiento de las potencialidades adormecidas en el alma humana del hombre enfermo, no de una disfunción cerebral - que también es posible — pero enfermo por falta de amor, cariño, comprensión e interés. El terapeuta es sensible a cada trasformación. El poeta Neruda, salvo en las veces que recitó en plaza pública sus poemas, no controló ni pudo percibir el alcance de sus creaciones sin tener el retorno de alguien, aún como el escrito del filósofo y del psiquiatra: el verbo camina más allá de la carne.

Conocer la persona que está delante nosotros, en su modo de ser, siempre ultrapasará cualquier objetividad en nosografía, aún que sea presente y clara, hay algo de obscuro que no aparece, no porque ese algo está escondido, tal vez porque solo pueda manifestarse si encontrado. ¿Que podemos delante un ser que sufre, que sufre como yo, porque humano, como tú y como él, pero que su sufrimiento lo paraliza, bloquea, lo torna inmóvil? Paradoja completa, ningún ser humano está completamente paralizado, la esperanza que palpita en el corazón humano que lo diga. Si un hombre que sufre no encuentra otro hombre interesado y en devoción, seguirá buscando a sí mismo en el otro, de modo que la esperanza sea combustible para mantenerse vivo.

Los manuales clasificatorios, tan importantes cuanto imprescindibles a la medicina psiquiátrica, que no podemos negar dada la necesidad de tales diagnósticos para determinados cuadros, aún que los critiquemos filosófica y clínicamente, encuentran en el poeta, en el artista, en el fenomenólogo puro, limites intrasponibles. "De niño y de grande anduve mucho más entre ríos y pájaros que entre bibliotecas y escritores. También asumí el deber antiguo de los poetas: la defensa del pueblo, de la pobre gente explotada" (Neruda, 2003, p. 132). La defensa de la gente explotada por un sistema socio, político y económico. Para Henry (2001) tanto el capitalismo cuanto el socialismo degradaron la condición humana, fallaron. Neruda sufrió delante la guerra española y ya previa lo que pasaría en América del Sur. En movimiento, en contacto y ligación íntima con la naturaleza en proporción tan importantes cuanto los libros, Neruda anduvo en defensa de la comunidad humana explotada, violada por el sistema político y económico de un país, tan común en cualquier rincón de este planeta, de países habitados por dirigentes deshumanos. 
Neruda (2003) se vía como un ser más común que los que lo idealizaban, en su opinión, porque temían un reino peligroso a ellos: "el de la comunicación cantante entre los seres humanos" (p. 132).

De la "comunicación cantante" a las metáforas utilizadas por Eugène Minkowski (1973), el médico de nuestro trabajo, cuando empezaba a mostrar lo que sería su análisis fenómeno-estructural en psicopatología, la más personal posible que reguardaba aspectos humanos poco interesantes a modas y reproducción fácil de constataciones comportamentales, visibles, utilizaba metáforas próximas al canto humano, que solo pueden ser reconocidas por un espíritu humano, abierto y sensible a las metáforas de las melodías, de las músicas que surgen entre dos humanos, cuando están en diapasón o no (Minkowski, 1968), en sintonía o no con el otro, reconociendo y acreditando a Bleuler esta expresión sintónica y también la que rompe en esquizoidia. Por veces se reconocían — médico y paciente, otras veces no.

¿Ya que en este ensayo el hombre esta prójimo a la naturaleza y vida del animal, cual es la música que toca la naturaleza de la relación humana? Son infinitas, sería imposible nombrarlas, la musicalidad del mar, de los truenos, de los volcanes, del viento. ¿Y los animales? Cuantos cantaros de pájaros agradan a unos, incomodan a otros. Solo nuestra dimensión humana, que nos hace distintos de la vida biológica y animal (al mismo tiempo que la contiene en Sí), puede dar sentidos a la música en la intersubjetividad, en la intropatia, posible con el árbol, posible con nuestro perro, pero que toma una sofisticada y más complexa variaciones de fenómenos delante nuestro semejante.

Minkowski (1973) refiere el uso de metáforas musicales que lo ayudan a comprender el modo de ser de un semejante con esquizofrenia melancólica. Por momentos el paciente entraba en sintonía y ligación con el psiquiatra, otras veces la esquizoidia prevalecía en sus delirios persecutorios; por un lado la afinación sintónica, por otra "dos melodías que ya no se reconocen" (p. 169-181). El psiquiatra polonés, radicado en Francia, comprendió en su época que el tiempo exigido durante las guerras mundiales ya no respetaba el tiempo íntimo, las vivencias temporales. Su interés por el tiempo vivido lo llevó a reconocer que delante ese paciente, el tiempo futuro del médico estaba presente, pero el devenir del paciente, afectado, cerrado, imposibilitado. La vivencia de espacio del médico era restricto, pero infinito en su paciente, lo que llevaba a este último — entre otros motivos — a una angustia sin fin.

Minkowski falleció en 1972, época que nuestro poeta Neruda luchaba a favor de un ideal, de una ideología que llevaba en cuenta la comunidad humana, el socialismo en América Latina. Sabemos que desde las grandes guerras se instaló en el mundo el capitalismo y las relaciones humanas en el trabajo y personales fueron afectadas, hasta ahora la son, en la revolución virtual y mediática en la cual las relaciones de las vivencias del tiempo personal sufren y tienen que relacionarse, 


\section{MOVIMENTOS LITERÁRIOS}

encuentran también nuevas formas de relacionarse y comunicarse. ¿Habría Neruda luchado en vano al lado de su amigo Salvador Allende y del pueblo usando como arma la poesía? Dicen que murió por un cáncer en la próstata, hoy ya existen estudios que cuestionan su muerte (Amorós, 2012).

Los nuevos estudios muestran que los años pasan y el dolor de una dictadura se torna para la historia humana necesaria e inolvidable. La memoria nos hace conocer aún más. Matilde Urrutia cuenta que en el día 22 de septiembre de 1973 (once días después del golpe), Manuel Arraya encontró Neruda en el Hospital Santa María, muy alterado porque se enteró por agentes del régimen de Augusto Pinochet del cruel asesinato al cantor y también poeta popular Víctor Jara. Le dieron calmantes y le aplicaron una inyección para conciliar el sueño, hasta que se durmió. "No despertó de nuevo: un paro cardíaco acabo con su vida a las diez y media de la noche del 23 de septiembre de 1973" (Amorós, 2012, p. 16). El cáncer debido a la próstata estaba controlado. Sufrimiento en la carne, en el alma.

Otros datos cogidos de la memoria humana por Amorós (2013) reescriben capítulos de la historia, aún desconocidos. La muerte de un artista sigue palpitando en los vivos. Su chofer comento: "A Neruda lo mataron". Dos días después, el diario popular principal do Chile discutió la acción de una inyección y los efectos para la salud. Durante quatro décadas se cuestionó la causa de la muerte de Neruda. Él militó en el partido comunista de Chile desde 1945, fue senador, candidato presidencial en 1969 y miembro del comité central.

Amorós $^{1}$ (2012) cuenta que la Clínica Santa María estuvo envuelta en otro misterio, el asesinato de Eduardo Frei Montalva, presidente de Chile entre 1964 y 1970. Falleció Frei de una forma inesperada, sometido a una cirugía digestiva menor. Tal clínica fue acusada de tener relación con el ejército, que dice que en cuanto hospitalizado Neruda fue envenenado con Talio y "gas mostaza" aplicadas por agentes de la Central Nacional de Informaciones, con los cuerpos represivos de la dictadura. Matilde siempre negó las razones oficiales de la muerte del poeta y ella le confesó a una enfermera, Rosa Núñez, que sospechaba que su esposo había sido asesinado con una inyección.

También Michel Henry sufrió en la clandestinidad, la Segunda Guerra Mundial, muy joven, con sus veinte y pocos años. Conoció los países comunistas y se impresionó con la falta de ética del este europeo. Diferente de Neruda, que en sus

${ }^{1}$ Amorós (2012) viajó en Chile para recompilar toda información contundente, para apoyarse con rigor en toda fuente posible, sino también para prevenir cualquier desviación hacia el sensacionalismo. Neruda vio la guerra civil en España instigada por el fascismo que dominaba en Alemania y en Italia, tal movimiento destructivo dejaron un millón de muertos y medio millón de españoles en el destierro (pp. 73-74). 
visitas a Rusia, se tornó uno de los defensores de la parte — tal vez — más bonita de ese sistema, la vida comunitaria a todos, Henry escribe La barbarie después de doce años de cuidadoso labor. Critica ambos sistemas comunista y capitalista porque denegrían la dignidad humana (Henry, 2008).

Buscamos con la interlocución entre Neruda, Henry y Minkowski la posibilidad de enfocar el pathos humano por tres diferentes vértices, que buscan sostener la condición humana en lo que tiene de más originario. La polifonía es un método que nos permite abordar la condición humana de modo a no reducir su complexidad. La concepción de la polifonía fue presentada por Bakhtin (1974) en el campo de la teoría literaria y la filosofía del lenguaje y se extendió por el campo de las Ciencias Humanas, como un método legítimo de producción del conocimiento. En cuanto método, la polifonía nos presenta una perspectiva dialógica que incluye la cuestión de la alteridad, dimensión ética fundamental en la actualidad. Bakhtin (1974) afirma:

Não há uma palavra que seja primeira ou a última, e não há limites para o contexto dialógico (este se perde num passado ilimitado e num futuro ilimitado) (...). Em cada um dos pontos do diálogo que se desenrola, existe uma multiplicidade inumerável, ilimitada de sentidos esquecidos, porém, num determinado ponto, no desenrolar do diálogo, ao sabor de sua evolução, eles serão rememorados e renascerão numa forma renovada (num contexto novo). Não há nada morto de maneira absoluta. Todo sentido festejará um dia seu renascimento. (pp. 413-414)

Para hacer ciencia es necesario sustentar la objetividad de la producción de conocimiento contemplando la mirada ética delante del ser humano. El monolingüismo implicaría la supresión de las diferentes voces implicadas en nuestro objeto de investigación. La polifonía se refiere a la pluralidad de voces necesaria para el desarrollo de una modalidad de investigación asentada en la fundación de un pensamiento complejo, ético y político. Horizonte fundamental para la visión de la vida de nuestros autores.

Neruda nos dejó una obra, Minkowski y Henry también. Lo que tienen en común fue delatar la violencia hacia la vida humana y un gran respecto por el ser humano. Pero una pregunta se coloca a respecto del tema de este trabajo. ¿Que

${ }^{2}$ No hay una palabra que sea primera o la última, y no hay límites para el contexto dialógico (este se pierde en un pasado ilimitado y en un futuro ilimitado) (...). En cada uno de los puntos del diálogo que se desarrolla, existe una multiplicidad innumerable, ilimitada de sentidos olvidados, sin embargo, en un determinado punto, en el desarrollar del diálogo, al sabor de su evolución, ellos serán recordados y renacerán en una forma renovada (en un contexto nuevo). No hay nada muerto de manera absoluta. Todo sentido festejará un día su renacimiento (Bakhtin, 1974, p. 413-414, nuestra traducción). 


\section{MOVIMENTOS LITERÁRIOS}

tienen a ver con psicopatología? Todo y nada, mucho y poco. Como enunciado anteriormente, psicopatología es comprendida aquí como un modo del ser humano reaccionar a las adversidades de la vida en si, como una organización establecida por la ausencia y por la presencia de la compañía de otro ser humano, pero, aún que la persona la tenga en el íntimo del sí mismo, el cuerpo sufre y entra en jubilo de la misma manera. En algún momento de la vida, más allá del körper, más allá del Leib, el cuerpo vivo sueña despertar.

Cuerpo humano que tiene movimiento, sufre y se satisface, cuerpo humano que comprende la vida y su núcleo, que tiene como su esencia la afectividad (Henry, 1963). Somos afectados por la vida de los otros, de la cultura, pero antes de esta afección, somos auto-afectados por la vida en nosotros, como una auto-donación de sí, de nuestra vida más íntima que no podemos nos separar, ni distanciarnos (Henry, 1990).

El pathos a partir de la fenomenología de la vida de Michel Henry, nos remite a repensar la palabra Pathos, ahora como sufrimiento y satisfacción, considerando el pasaje de la dialéctica de los afectos. Cuando un ser humano se siente en el poder de su sentimiento, sin nada poder hacer y cuando puede transformarlo en sentimiento de poder. Para lograr esta posibilidad, puede hacerlo solo o en compañía, aquí entra el importante rol de los terapeutas. No basta la auto afección de la vida sin sintonía con la alteridad, con ella y en ella rescatamos la dignidad humana.

De cualquier modo tanto el médico Minkowski, el filósofo Henry y el poeta Neruda se interesaron en ayudar a mejorar y comprender la condición humana. Como todos los terapeutas que usan como principal instrumento de auxilio al otro su propia personalidad, bien acompañada de la literatura, de la pintura, de la música, en fin, de la sensibilidad. Hay algo de poético en la clínica, en el contacto con la psicopatología humana y por tanto con lo que es artístico, si podríamos decir así. Los poemas ayudan a la vida de todos y de cada uno, nos ayudan a nuestra propia vida a "sentirse a sí misma, experimentarse a sí misma" (Henry, 2008, p. 142).

Cuando Neruda se niega a masticar teorías lo aproximamos de la fenomenología de Michel Henry, que por su vez afirma que "al ser representada, la vida pierde pues lo que es, la inmediación patética donde encuentra su felicidad" (Henry, 2008 , p. 142). De cierta forma es lo que puede ocurrir con corrientes de la psicopatología que se sustentan en teorías. En ese sentido, en la esencia del arte "el tema de una obra no es lo que representa, un dato objetivo, sea la naturaleza o la vida, sean acontecimientos o sentimientos. El tema de una obra es su pathos de colores y formas" (p. 144). El pathos toma una connotación que nos es negativa, sino la vida misma. En la vida el arte, que "no representa nada: ni mundo, ni fuerza, ni afecto, ni vida" (p. 144). El arte no representa vida, es la pura manifestación de la vida. En su forma y en sus colores. "El arte es, en verdad, un modo de la vida y, por esta razón, en definitiva, un modo de vida (...) La vida está presente en el arte según su esencia 
propia" (p. 145). Podemos pensar en la literatura como un arte que toca la esencia de la vida, o la propia manifestación de la vida. Así también el trabajo clínico no deja de ser un trabajo artístico.

Si tomarmos la obra de Neruda para discutir esa cuestión, nos damos cuenta que el poeta mantiene en sus textos una nostalgia permanente por la propia historia original y el pueblo, en los cuales lo simple y la tierra es el horizonte de la vida. Delante de la opresión y desarraigo de lo étnico, lo que podría venir a ser una angustia impensable, gracias a la habilidad de crear poesía, Neruda tornase un portavoz de lo que es originario y de lo que es histórico. A través de sus textos, el poeta crea un campo de experiencias, que pone al lector en contacto con los orígenes de lo que significa ser sud americano. En sus textos, el lector puede encontrar el sentido de la dignidad de su origen. Estamos delante de la praxis poética que es también una acción política. El poeta tiene la capacidad de despertar en el lector el amor por el origen. ¿Pero de qué lugar habla Neruda? Sus poemas están escritos con sangre para ser escuchados con sangre. Es decir, es un sufrimiento (pathos) que genera estos poemas. ¡El dolor alcanza voz!

También en nuestra tarea clínica algo similar sucede, necesitamos comprehender que el padecimiento de nuestros pacientes necesita llegar a la expresión. La voz del dolor es personal pero es al mismo tiempo habla a todos. Hay una búsqueda de diálogo en el poeta y en el paciente con los seres de la historia, en la historia.

Neruda por medio de su pathos tiene esa mirada a la tierra con todo lo que significa la tierra, no sólo como un lugar de nacimiento, pero también como el origen étnico y cultural, no sólo como material de un hombre de trabajo, sino como un lugar del simple. El llora la tierra, grita a través de la opresión, porque eso significa, sobretodo, la ruptura con la tierra: el desarraigo. La desconexión con la tierra lleva a la pérdida del contacto con el cuerpo y con las cosas.

Durante el desarrollo de un niño, hay una relación con las cosas que se dan por la medida de su propio cuerpo, que mide el mundo en la palma de su mano. Es un mundo que es la medida de la corporeidad. Es un momento en que el niño está en contacto con las personas, de tal manera que conserva las dimensiones y los orígenes de lo que es tener un cuerpo humano.

A eso respecto Henry (2003) nos dice:

Nuestro cuerpo es un poder, pero este poder es un saber inmediato de sí, un saber que no presupone que estemos antes abiertos al horizonte de la verdad del Ser, sino que por el contrario, es el fundamento y el origen de esta verdad. (p. 129)

Tal como Minkowski orientó sus investigaciones en la estructura espaciotemporal de las perturbaciones mentales, los datos fenomenológicos y psicopatológicos han estado entremezclados, que no pueden ser separados porque son 


\section{MOVIMENTOS LITERÁRIOS}

miembros de una misma familia, forman "un todo vivo e indivisible". Henry aporta que la vida, donde la esencia es la afectividad, asentada en la corporeidad, aparece en Minkowski integrada a la psicopatología. El afirma que todas las manifestaciones de nuestra actividad mental no eran otra cosa que "las diversas expresiones de la vida misma y debían, por ello, ser tomadas en consideración si se pretendía seriamente asumir la tarea de penetrar su esencia" (Minkowski, 1973, p. 162). Más adelante, Minkowski coloca la afectividad en primer plan: "todo el lado afectivo de los trastornos mentales (...) establecen, en cierta medida al menos, una corriente de simpatía entre nosotros y crean una comunión de ideas" (p. 165).

$\mathrm{Al}$ atender un paciente durante su estancia en la clínica el veía diariamente su enfermo. Al hablar de su delirio, comenta Minkowski (pp. 165-167): "un día, a fuerza de escucharle el desarrollo de las mismas ideas, siento surgir en mí un sentimiento particular, sentimiento que mentalmente traduzco con las palabras "lo sé todo de él" (p. 165). Después de estar con su enfermo, Minkowski dirige su mirada hacia sí mismo, descubre que se sentía presa de un malestar, "como si al contacto con mi enfermo algo se rompiera en mí" (p. 165). Este conocimiento tenía un carácter práctico, relativo, lo que es desconocido parece constituir el fondo mismo del ser humano. "Este fondo, precisamente en lo que tiene de desconocido, constituye, como sabemos, la base común que nos liga a los demás seres humanos y hace de ellos, de forma inmediata, nuestros 'semejantes'. (...) puedo conocer a alguien, pero en el fondo nada sé de él. Esto constituye el valor de la vida" (p. 166). Así Minkowski muestra como "falta el fondo común con nuestros semejantes (...) fondo movedizo que constituye la vida en general (...) profundo, potente y misterioso es el fondo de donde brota nuestra vida, de donde brotan nuestras ideas, nuestros sentimientos, nuestras tendencias" (p. 167).

En las palabras de Neruda (1950, p. 629):

Entre los seres, como el aire vivo, y la soledad acorralada salgo a la multitud de los combates, libre porque en mi mano va tu mano, conquistando alegrías indomables.

En trabajo anterior, Ferreira \& Antúnez (2013) discuten la intersubjetividad en Michel Henry y la relación terapéutica. El concepto central de la Fenomenología da Vida es el Fondo común. Los humanos forman una comunidad de vivos y compartimos el Fondo común de la Vida. Nacemos en este Fondo y él no es diferente de nosotros, pero se manifiesta, se identifica y se particulariza en cada uno por medio de la auto-afección de la vida en nosotros. Por tanto, en el "Si" sucede, simultáneamente, una partilla colectiva de la Vida y a su revelación 
particular a cada uno de nosotros. La experiencia del otro se inicia en este Fondo común. Afirma Henry (2005) que la experiencia primitiva es casi impensable, porque escapa a todo pensamiento. El vivo no es para sí más que el otro, "él es tan solo una pura prueba sin sujetos, sin horizonte, sin significación, sin objeto. Lo que el prueba es idénticamente el mismo, el Fondo de la vida, el otro en cuanto él es también ese Fondo - entonces él prueba el otro en ese Fondo y no en él mismo, en cuanto la propia prueba que el otro hace del Fondo. Esta prueba es otro que tiene el Fondo en sí como el yo tiene el Fondo en él. Pero eso ni el yo ni el otro representan. Por eso es lo Mismo en el cual se abisman uno y otro" (pp. 144-145, nuestra traducción).

La relación con el otro se establece en ese registro del Fondo común, porque todos somos igualmente donados en la Vida y compartimos el mismo origen. Este tipo de comunicación primordial con la alteridad es irrepresentable, porque ocurre a través de la afectividad, esencia de la comunidad (Ferreira \& Antúnez, 2013).

En la comunidad que se establece entre el terapeuta y el paciente encontramos un rol importante en el afecto delante un ser que sufre. Minkowski (2001) y su amigo Binswanger muestran como el diagnóstico por sentimiento o penetración, la simpatía intelectual, se torna para Minkowski tan importante o más que el diagnóstico sintomático hecho por la razón, sea de un psiquismo normal o patológico "constituye un acto particular, caracterizado, ante todo, por el hecho de que se liga siempre al presente, y nace, se afirma y se agota en sus límites" (Minkowski, 1973, p. 208). El síndrome mental no es para Minkowski "una simple asociación de síntomas, sino la expresión de una modificación profunda y característica de la personalidad humana entera" (p. 209). En esta perspectiva, no vemos al enfermo delante nosotros como teniendo problemas en órganos o funciones, "sino con la personalidad viviente, una e indivisible. Nuestro pensamiento científico deberá comprometerse por completo en este campo. La interpretación de los síntomas y, en general, de todas las perturbaciones mentales, sufrirá necesariamente el contragolpe" (p. 210).

¿Al estar delante de una persona buscamos saber cuál es la esencia de sus dificultades y en su vida? Henry buscaba saber cuál es la esencia de la vida, al que el mismo responde: "No solamente la experiencia de sí, sino, como su consecuencia inmediata, el crecimiento de sí. Experimentarse a sí mismo, al modo de la vida, es llegar a sí mismo, entrar en posesión del propio ser, crecer en uno mismo, ser afectado por un 'plus' que es el 'plus de sí mismo'. Y este 'plus' no es objeto de una mirada, de una evolución cuantitativa: como incremento de sí y como experiencia del ser propio, es una manera de gozar de sí, es el goce. Por eso la vida es un movimiento: el movimiento eterno que implica el paso del Sufrimiento a la Alegría - en la medida en que la experiencia que la vida hace de sí es un Sufrir primitivo —-, ese sentimiento de sí que la entrega a sí misma, en el gozo y en la embriaguez de sí” (Henry, 2008, p. 145). 


\section{MOVIMENTOS LITERÁRIOS}

Hay en Michel Henry (2008) otra noción interesante para pensar la clínica, es la "pasividad radical de la vida respecto de sí misma y, en esta imposibilidad de no ser ella misma, de separarse de sí, de ponerse a distancia, de escapar de sí, la obligación que se le impone de ser lo que es hasta el final y para siempre, de agotar todas sus posibilidades y vivir" (p. 148). Es curioso que personas busquen un extraño para compartir su vida, de la cual no pueden escapar, por lo contrario, todo ser humano está condenado a vivir lo que es, a sentir su vida, a ser auto-afectado por Sí, antes de ser por el otro. Ya el extraño se torna familiar, aún más importante que muchos.

Neruda, Minkowski, Henry, todos preocupados por la vida, no de lo visible, sino de lo invisible, como desarrolla Henry (2008): “¿Por qué es sagrada la vida? Porque la vivimos en nosotros como lo que no hemos proyectado ni querido, como lo que nos atraviesa sin que seamos su causa: a nosotros, que no somos ni hacemos nada más que ser impulsados por ella (p. 149). Esta pasividad en nosotros de la vida respecto de sí es nuestra subjetividad patética; el contenido invisible, abstracto, del arte eterno, de la pintura" (p. 150).

Vivimos en un tiempo y mundo científico que cree poder dejar de lado las cualidades sensibles del propio mundo material y sus formas ideales, conocimiento geométrico y matemático, "riguroso", "objetivo" y "científico" (p. 150). Para Henry, el proyecto de Galileo, más allá del sentido metodológico, implica la supresión de la pintura, cuyos elementos son todas cualidades sensibles y es justamente la vida que es eliminada. Sea la pintura, el poema, la metáfora, tratan de hacer ver en un mundo: ya no representan el mundo, es la vida, la vida invisible y sus tonalidades: "la fuerza, la alegría, el amor, el perdón, la purificación, el don; la afirmación de la vida por ella misma y contra la muerte: la fe, la certeza, la confianza en sí mismo. Y sus 'contrarios', que existen en forma de afectos: el miedo, la duda, la envidia, el tedio, el orgullo, la crueldad, el desamparo, la lujuria, la gula, el sufrimiento. Ciertamente, no percibimos ninguno de esos sentimientos directamente y en sí mismo porque, igual que la vida que lo habita y hace de él lo que es, un sentimiento es invisible" (p. 151).

Es la humanidad del Hombre la que está en peligro en la Vida y en su vida, no sólo en la contemporaneidad, sino tal vez desde que nos conocemos como tal. De tal forma que vivimos nuestra Vida íntima independiente de la exterioridad, aún convivimos con ella. Vivimos acompañados por nuestro Telos, una certeza que jamás la conoceremos, sino que la viviremos en un segundo. La noción negativa que distraídamente se puede pensar la psicopatología, la sustituyamos por el estudio del sufrimiento (Sufrimiento logia), con sus modalidades dinámicas de transitar entre el bello y el trágico, sufrimiento es vida, ella es sufrimiento:

Tal vez es este el fin, la verdad misteriosa.

La vida, la continua sucesión de un vacío 
Que de día y de sombra llenaban esta copa

$\mathrm{Y}$ el fulgor fue enterrado como un antiguo príncipe

En su propia mortaja de mineral enfermo,

Hasta que tan tardíos ya somos, que no somos:

Ser y no ser resultan ser la vida.

De lo que fui no tengo sino estas marcas crueles

porque aquellos dolores confirman mí

existencia.

(Neruda, 1999, p. 109)

\section{Referencias}

Amorós, M. (2012). Sombras sobre Isla Negra. La misteriosa muerte de Pablo Neruda. Santiago: Ediciones B Chile S.A.

Bakhtin, M. (1974). Epistemologia das Ciências Humanas. In Estética da criação verbal. São Paulo: Martins Fontes.

Ferreira, M. V., \& Antúnez, A. E. A. (2013). Intersubjetividade em Michel Henry: relação terapêutica. Revista da Abordagem Gestáltica, 19(1), 92-96. Recuperado em 18 de fevereiro de 2014, de <http://pepsic.bvsalud.org/scielo.php?script=sci_arttext\&pi$\mathrm{d}=\mathrm{S} 1809-68672013000100012 \& \operatorname{lng}=\mathrm{pt} \& \mathrm{t} \operatorname{lng}=\mathrm{pt}>$.

Henry, M. (2001). La barbarie. Paris: PUF.

Henry, M. (2003). Philosophie et phenomenologie du corps. Paris: PUF. p. 129.

Henry, M. (2005). Fenomenologia material. Maia, Portugal: Ed. Fomento.

Henry, M. (2008). Ver lo invisible - Acerca de Kandinsky. Madrid: Ediciones Siruela. (Originalmente publicado en F. Burin 1998; PUF, 2004).

Henry, M. (2008). Du communisme au capitalisme: théorie d'une catastrophe. Suisse: L'âge d'homme.

Henry, M. (2011). L'essence de la manifestation. (4 $4^{\mathrm{eme}}$ édition). Paris: PUF. (Trabalho originalmente publicado em 1963).

Minkowski, E. (1968). Le temps vécu. Suisse: Delachaux et Niestlé S.A.

Minkowski, E. (1973). El tiempo vivido. México: FCE. pp. 169-181.

Minkowski, E. (2001). La esquizofrenia - Psicopatología de los esquizoides y los esquizofrénicos. México: FCE.

Neruda, P. (1950). Canto general. México: Talleres Gráficos de la Nación.

Neruda, P. (1999). Memorial de Isla Negra. Buenos Aires: Seix Barral.

Neruda, P. (2003). Para nacer he nacido. Buenos Aires: Seix Barral. 


\section{MOVIMENTOS LITERÁRIOS}

Ramón, A. de (2003). Historia de Chile. Desde la invasión incaica hasta nuestros dias (1500-2000). Santiago: Catalonia.

Safra, G. (2006). Hermenêutica na situação clínica - o desvelar da singularidade pelo idioma pessoal. São Paulo: Sobornost.

\section{Resumos}

(O poeta, o filósofo, o médico: estudo do sofrimento)

O presente trabalho realiza uma interlocução entre um poeta, um fenomenólogo e um psicopatólogo, on de o eixo comum é a clínica terapêutica e uma compreensão possível da psicopatologia em diálogo interdisciplinar. Observamos que a literatura, a filosofia e a medicina psiquiátrica contribuem para compreender o sofrimento humano não só como uma manifestação psíquica, mas intimamente relacionado à sensibilidade, a afetividade e a vivência pessoal do tempo e espaço humanos em direção aos fatores ambientais e culturais.

Palavras-chave: Literatura, fenomenologia, psicopatologia, psicologia clínica

(The poet, the philosopher, the physician: a study on suffering)

This paper consists of a dialogue among a poet, a phenomenologist and a psychopathologist. Their common ground is the therapeutic clinic and a possible understanding of psychopathology in an interdisciplinary dialogue. We hold that literature, philosophy and psychiatric medicine help us understand human suffering not only as an intrapsychic event, but closely related to the sensitivity, affectivity and personal experience of human time and space in connection with environmental and cultural factors.

Key words: Literature, phenomenology, psychopathology, clinical psychology

(Le poète, le philosophe, le médecin: étude sur la souffrance)

Cet article établit un dialogue entre un poète, un phénoménologue et un psychopathologue, dont l'axe commun est la clinique thérapeutique et une possible compréhension de la psychopathologie à travers le dialogue interdisciplinaire. Nous observons que la littérature, la philosophie, la médecine et les soins psychiatriques contribuent à comprendre la souffrance humaine non seulement comme manifestation psychique, mais comme phénomène étroitement lié à la sensibilité, à l'affectivité et à l'expérience personnelle du temps et de l'espace humains par rapport aux facteurs environnementaux et culturels.

Mots clés: Littérature, phénoménologie, psychopathologie, psychologie clinique 
(Der Dichter, der Philosoph, der Arzt: eine Studie des Leidens)

In diesem Beitrag wird ein Gespräch zwischen einem Dichter, einem Phänomenologen und einem Psychopathologen geführt, dessen gemeinsame Achse die therapeutische Klinik und eine mögliche Auffassung der Psychopathologie im interdisziplinären Dialog ist. Es wird beobachtet, dass die Literatur, die Philosophie und die psychiatrische Medizin dazu beitragen, dass das menschliche Leiden nicht nur als eine psychische Äußerung gesehen wird, sondern eng mit der Sensibilität, dem Affekt und dem persönlichen Erleben von menschlicher Zeit und Raum in Bezug auf Umweltfaktoren und kulturellen Faktoren verbunden ist.

Schlüsselwörter: Literatur, Phänomenologie, Psychopathologie, klinische Psychologie

Citação/Citation: Antúnez, A. E. A., \& Safra, G. (2014, junho). El poeta, el filósofo, el médico: estúdio del sufrimiento. Revista Latinoamericana de Psicopatologia Fundamental, 17(2), 363-376.

Editor do artigo/Editor: Dr. Ricardo Telles de Deus

Recebido/Received: 14.3.2014/3.14.2014 Aceito/Accepted: 18.4.2014 / 4.18.2014

Copyright: (C) 2009 Associação Universitária de Pesquisa em Psicopatologia Fundamental/ University Association for Research in Fundamental Psychopathology. Este é um artigo de livre acesso, que permite uso irrestrito, distribuição e reprodução em qualquer meio, desde que o autor e a fonte sejam citados / This is an open-access article, which permits unrestricted use, distribution, and reproduction in any medium, provided the original author and source are credited.

Financiamento/Funding: Os autores declaram não ter sido financiados ou apoiados / The authors have no support or funding to report.

Conflito de interesses/Conflict of interest: Os autores declaram que não há conflito de interesses / The authors declare that has no conflict of interest.

\section{Andrés Eduardo Aguirre Antúnez}

Professor Livre-docente do Instituto de Psicologia da Universidade de São Paulo - USP (São Paulo, SP, Br), Departamento de Psicologia Clínica.

Av. Prof. Mello Moraes, 1721 - Cidade Universitária 05508-030 São Paulo, SP, Br

e-mail: antunez@usp.br

\section{Gilberto SAFra}

Professor Titular do Instituto de Psicologia da Universidade de São Paulo - USP (São Paulo, $\mathrm{SP}, \mathrm{Br})$, Departamento de Psicologia Clínica.

Av. Prof. Mello Moraes, 1721 - Cidade Universitária

05508-030 São Paulo, SP, Br

e-mail: iamsafra@usp.br 